\title{
Determination of avocado maturity by ultrasonic attenuation measurements
}

\author{
A. Mizrach ${ }^{\mathrm{a}, *}$, U. Flitsanov ${ }^{\mathrm{a}}$, R. El-Batsri ${ }^{\mathrm{b}}$, C. Degani ${ }^{\mathrm{b}}$ \\ ${ }^{\mathrm{a}}$ Institute of Agricultural Engineering, Agricultural Research Organization (ARO), The Volcani \\ Center, P.O. Box 6, Bet Dagan 50250, Israel \\ ${ }^{\mathrm{b}}$ Institute of Horticulture, Agricultural Research Organization (ARO), The Volcani Center, \\ P.O. Box 6, Bet Dagan 50250, Israel
}

Accepted 5 October 1998

\begin{abstract}
A non-destructive ultrasonic method was evaluated for the determination of avocado (Persea americana Mill.) maturity. Fruit of 'Ettinger' and 'Fuerte' avocado cultivars were sampled from tagged trees in the orchard throughout the fruiting season on six and five dates, respectively. Each fruit was subjected to ultrasonic measurements in which ultrasonic mechanical waves were excited in the avocado flesh, enabling the attenuation of waves to be calculated. The dry weight (DW) content of fruit was assessed for the determination of avocado maturity. The changes in attenuation of the ultrasonic signal and those in DW content, during the fruiting season, were functions of time in opposite tendencies: a monotonic decrease in attenuation and a monotonic increase in the DW content. The two cultivars yielded similar tendencies for attenuation and DW content. The relationship between attenuation and DW content suggested that the degree of avocado maturity can be determined by ultrasonic non-destructive technology. (C) 1999 Elsevier Science B.V. All rights reserved.
\end{abstract}

Keywords: Ultrasonic; Non-destructive testing; Maturity; Quality; Fruit; Avocado

\section{Introduction}

Maturity is a major component of avocado quality and a prime factor in palatability. Maturity is essential to determine the date of fruit harvest. Oil

* Corresponding author. Tel:. +972-3-9683451; fax: +972-3-9604704; e-mail: amos@agri.gov.il

0304-4238/99/\$ - see front matter (C) 1999 Elsevier Science B.V. All rights reserved.

PII: S 0304-4238(98)00243-X 
content and dry weight (DW) content are the most accepted indices of avocado maturity. These two parameters increase with fruit development (Lee et al., 1983; Blumenfeld and Degani, 1987). Immature avocado do not ripen properly, do not attain an acceptable taste and over-ripe fruit decay rapidly after harvest. A small quantity of over-ripe fruits in a shipment may trigger a chain reaction and cause pre-mature ripening of the whole shipment (Zauberman and Fuchs, 1981). In Israel, $20.5 \%$ DW content (equivalent to $9 \%$ oil content) is the minimum maturity standard for 'Ettinger' and 'Fuerte' cultivars (Degani et al., 1986). The two methods for the determination of avocado maturity, oil content and DW content, are both destructive. A non-destructive method for the determination of avocado maturity would be of considerable economic interest for the avocado industry.

Mizrach et al. (1989) evaluated the use of high-power, low-frequency ultrasonic excitation for determination of fruit tissue properties, and suggested the application of this technique to the non-destructive quality evaluation of fruits and vegetables. An experimental system was designed for determination of the basic acoustic properties of some fruits and vegetables, i.e. wave propagation velocity and attenuation. In addition, Mizrach et al. (1991, 1992) found a strong interdependence between ultrasonic properties and post-harvest ripening parameters of the fruit tissue and patented a device for nondestructive determination of quality parameters of fruits (Mizrach et al., 1994). Recently, Mizrach et al. (1996) suggested a model for ultrasonic parameters to assess avocado properties and shelf life.

The objective of the present study was to analyze ultrasonic signals in avocado fruit ('Fuerte' and 'Ettinger') during growth, and to examine the relationship between the DW content and ultrasonic attenuation measurements in order to test the possible use of the ultrasonic technique for determination of avocado maturity.

\section{Materials and methods}

\subsection{Experimental setup}

A high-power, low-frequency ultrasonic pulser receiver (Krautkramer Model USL33) and a pair of $50 \mathrm{kHz}$ ultrasonic transducers were used to generate the signal coupled to a micro computer system for data acquisition and analysis. Exponential-type Plexiglas beam-focusing elements were used to reduce the $55 \mathrm{~mm}$ beam diameter of each transducer to the desired area of contact with the fruit. The transducers were mounted with an angle of about $120^{\circ} \mathrm{C}$ between their axes, enabling an ultrasonic signal to be transmitted and received over a short distance (minimum of $5 \mathrm{~mm}$ ) between their tips across the peel of the fruit (Mizrach et al., 1994). The head arrangement allowed relative motion of the 
ultrasonic probes while a controlled contact force on the fruit peel was maintained. The through-transmission mode was selected, with one transducer acting as a transmitter and the other as a receiver. The pulser caused the transmitter to oscillate and emit an ultrasonic pulse obliquely into the peel. The ultrasonic input energy induced waves over the peel and through the fruit tissue that activated the receiver. The output pulse was displayed on a cathode ray tube (CRT) and the pulse amplitude and transit time could be visually determined. In parallel, a built-in peak detector and microprocessor-controlled serial interface captured the signal amplitude and the transit time, and sent a digitized read-out to an external microcomputer. The stored data were used to determine the wave attenuation and calculate the fruit attenuation coefficient as described by Mizrach et al. (1989).

\subsection{Plant material}

The experiments were carried out during July-November 1996 on fruits taken from two plots of 8-year-old trees of 'Ettinger' and 'Fuerte' cultivars, each plot contained 400 trees. Ten trees per cultivar, distant from the plot edge or lane, were randomly tagged. 'Ettinger' fruit (20) were sampled on six dates: 13 July, 24 July, 30 August, 27 September, 22 October and 19 November. 'Fuerte' fruit (20) were sampled on the same dates except for 13 July. The fruit were equilibrated at $20^{\circ} \mathrm{C}$ and approximately $85 \% \mathrm{RH}$, for ultrasonic and DW content tests on the day of picking.

\subsection{Ultrasonic tests}

The peel of each fruit was marked at a point on the circumference at the largest cross section perpendicular to the blossom end - stem end axis ('equator'), for ultrasonic non-destructive testing (NDT). The pulse amplitude of the transmitted ultrasonic signal was measured at five different spacing $(5,12,14,16$ and $18 \mathrm{~mm})$ between the two probes, along the equator of the fruit, as described above. The attenuation of the ultrasonic signal was calculated (Krautkramer and Krautkramer, 1990): $A=A_{0} e^{-\alpha l}$ where $l$ is the distance between the input and collection probes, $A$ and $A_{0}$, respectively, are the ultrasonic signal amplitudes at the beginning and the end of a distance $l$ along the propagation path of the ultrasonic wave, and $\alpha$ is the apparent attenuation coefficient of the signal.

\subsection{Dry weight determination}

A sample (ca $10 \mathrm{~g}$ ) was taken from the location at which NDT had been performed earlier, and was weighed and dried at $65^{\circ} \mathrm{C}$ in a forced-air oven for $24 \mathrm{~h}$ and reweighed for DW percentage. 


\section{Results and discussion}

DW content for 'Ettinger' and 'Fuerte' increased and attenuation values decreased with time (Table 1). The increase in DW percentage has been shown to be closely related to fruit development (Lee et al., 1983). In Israel, a DW content of $20.5 \%$ for 'Ettinger' and 'Fuerte' is the minimum standard for maturity (Degani et al., 1986). The DW percentages on the last sampling date were $21.71 \%$ and $21.84 \%$ for 'Ettinger' and 'Fuerte', respectively, showing that both had reached maturity (Table 1). Attenuation decreased as fruit growth progressed (Table 1). The measurement results obtained at the last sampling dates showed mean attenuation of 2.61 and $2.40 \mathrm{~dB} \mathrm{~mm}^{-1}$, respectively. These results were consistent with mean attenuation values found on firm fruit, immediately after harvest in 'Ettinger' and 'Fuerte' avocados, in previous studies (Mizrach et al., 1994; Mizrach and Flitsanov, 1996).

The calculated attenuation of the ultrasonic waves in the avocado fruit, and the means of the DW content, were plotted for 'Ettinger' and 'Fuerte' (Fig. 1). For both the cultivars, the data points in Fig. 1 represent the mean value for each set of fruits at the different picking dates according to Table 1. The graph shows an increasing trend in DW and a decreasing trend in ultrasonic attenuation with fruit growth. Avocado DW increases with growth and does not change after harvest (Degani et al., 1986). However, the attenuation of the ultrasonic waves continues to change, decreasing with growth (Fig. 1) and increasing during the post-harvest softening and ripening process, until the fruit became very soft (Mizrach et al., 1996). The decrease in attenuation during growth and its increase during post-

Table 1

Mean values of ultrasonic and physiological properties, cv. 'Ettinger' and 'Fuerte' fruit; 20 fruits tested at each sampling date amendment

\begin{tabular}{|c|c|c|c|c|c|c|}
\hline Sampling picking date & 13.07 & 24.07 & 30.08 & 27.09 & 22.10 & 19.11 \\
\hline \multicolumn{7}{|l|}{ Ettinger } \\
\hline Dry weight, (\%) & 15.24 & 15.22 & 15.30 & 16.68 & 19.59 & 21.71 \\
\hline Dry weight $^{\mathrm{a}},(\%)$ & 0.97 & 0.44 & 0.71 & 0.82 & 1.31 & 1.29 \\
\hline Attenuation, $\mathrm{A}\left(\mathrm{dB} \mathrm{mm} \mathrm{m}^{-1}\right)$ & 4.54 & 3.62 & 3.47 & 2.94 & 2.66 & 2.61 \\
\hline Attenuation ${ }^{\mathrm{a}}, \mathrm{A}\left(\mathrm{dB} \mathrm{mm}^{-1}\right)$ & 0.81 & 0.78 & 0.74 & 0.56 & 0.77 & 0.57 \\
\hline \multicolumn{7}{|l|}{ Fuerte } \\
\hline Dry weight, (\%) & b & 14.68 & 14.50 & 15.80 & 18.58 & 21.84 \\
\hline Dry weight $^{\mathrm{a}},(\%)$ & $\mathrm{b}$ & 0.46 & 0.85 & 0.76 & 1.26 & 1.41 \\
\hline Attenuation, $\mathrm{A}\left(\mathrm{dB} \mathrm{mm} \mathrm{mm}^{-1}\right)$ & b & 4.61 & 4.25 & 3.21 & 2.86 & 2.40 \\
\hline Attenuation ${ }^{\mathrm{a}}, \mathrm{A}\left(\mathrm{dB} \mathrm{m}^{-1}\right)$ & $\mathrm{b}$ & 0.83 & 0.98 & 0.58 & 0.54 & 0.55 \\
\hline
\end{tabular}

${ }^{a}$ Standard deviation (SD).

${ }^{\mathrm{b}}$ Data were not taken. 

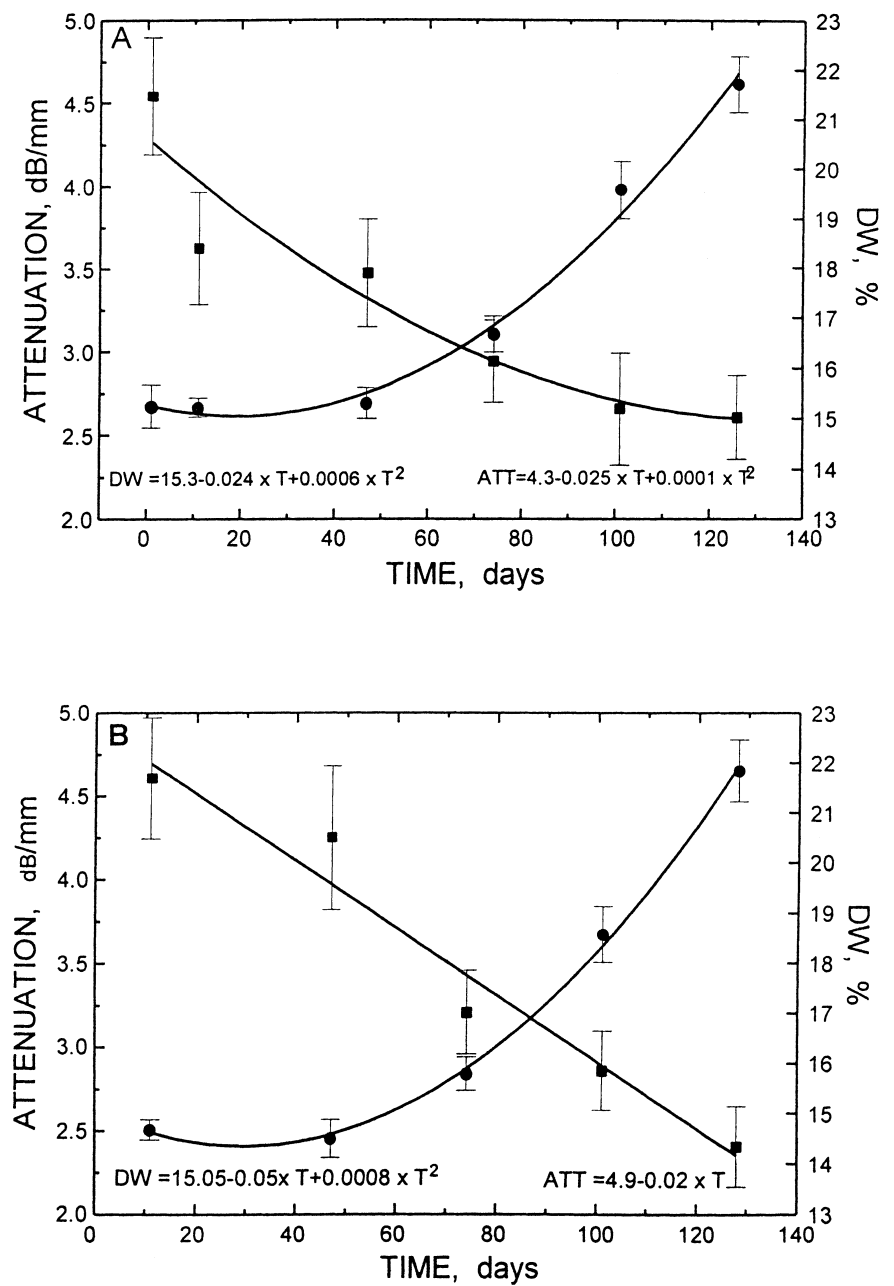

Fig. 1. The variation of the mean values of wave attenuation and dry weight content (DW) with growth time, for avocado fruit cv. (A) 'Ettinger' and (B) 'Fuerte'. •, DW; $\mathbf{m}$, attenuation. Each point represents the means value of 20 fruits. Vertical lines represent confidence intervals (confidence probability $=95 \%$ ).

harvest softening, result from different physiological processes and need further investigation.

A non-linear regression procedure was used to relate variations in ultrasound attenuation and DW to growth time. A simple curve fitted to the experimental results defined constants for the curves. A parabolic function was fitted to the mean values to describe the model relating the variation of DW with time and provided relatively good correlations $(R=0.9948$ and $R=0.9989$, for 'Ettinger' and 'Fuerte', respectively). A monotonic decrease in the attenuation of the 

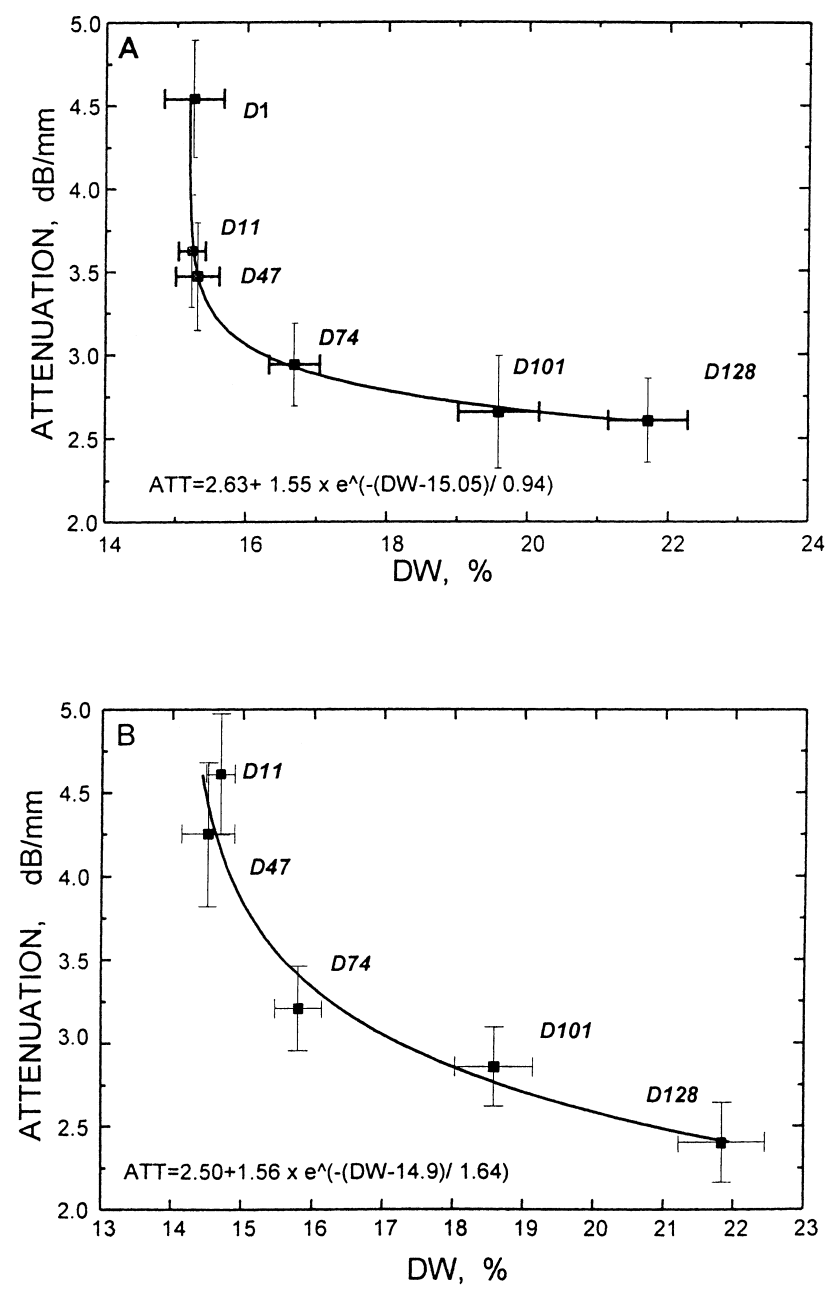

Fig. 2. Attenuation vs. DW content during growth time, for avocado fruit cv. (A)'Ettinger' and (B) 'Fuerte'. Vertical and horizontal lines represent confidence intervals for attenuation and DW, respectively (confidence probability $=95 \%$ ).

ultrasonic signal with time suggested selection of parabolic and linear curves for 'Ettinger' and 'Fuerte', respectively $(R=0.9496$ and $R=0.9800$, Fig. 1).

Since attenuation and DW were both time-dependent, a direct relationship was drawn between these two parameters (Fig. 2). An exponential expression was selected as the curve of 'best fit' in both cultivars. It was found that the DW for 'Ettinger' and 'Fuerte', correlated quite closely with the ultrasonic attenuation of the fruit on the same day $(R=0.8749$ and $R=0.9636$, respectively). The ultrasonic wave attenuation reduced with increasing DW content during fruit growth, but not at a constant rate; it reduced sharply during the July-October 
period of growth and moderately when the fruit approached maturity during October-November. According to the attenuation DW curve (Fig. 2), the ultrasonic attenuation asymptotically approaches an horizontal line. The DW content at that point, passed the minimum standard for maturity and indicated that the fruit had reached the appropriate harvest conditions. This phenomenon is clear for 'Ettinger' fruit. However, for 'Fuerte' fruit, the curve needed to decrease further until it asymptotically approached the horizontal line. This might indicate that 'Fuerte' fruit had not reached the appropriate harvest conditions.

In spite of the scatter, there was a reduced tendency of attenuation with increasing DW content, suggesting that the DW percentage in avocado could be evaluated by ultrasonic attenuation during fruit growth. However, repeated measurements on individual fruit may reduce the results scatter.

\section{Conclusions}

'Ettinger' and 'Fuerte' fruit showed similar increasing DW percentage and decreasing attenuation with fruit growth. A second-order polynomial represented the changes in DW content during fruit growth for 'Ettinger' and 'Fuerte' with relatively low scatter at each individual date. A second-order polynomial and a linear relation were fitted to the changes in attenuation of the ultrasonic signals during growth of these two cultivars, respectively. A direct relation between the DW and the ultrasonic attenuation of the tested fruits was found. Both attenuation and DW measurements showed scatter, but repeated measurements on individual fruits may reduce this scatter.

This relation may be usable as a non-destructive, pre-harvest determination of the DW percentage of avocado fruit and the precise determination of the harvest time.

\section{References}

Blumenfeld, A., Degani, C., 1987. Maturation and ripening of avocado fruits (in Hebrew). Alon Hanotea 41, 985-992.

Degani, C., Bechor, V., Albazri, R., Blumenfeld, A., 1986. Dry weight content as an index for determination of maturity of avocado fruits (in Hebrew). Alon Hanotea 40, 1017-1022.

Krautkramer, J., Krautkramer, H., 1990. Ultrasonic Testing of Materials. Springer, Heidelberg, Germany.

Lee, S.K., Young, R.E., Schiffman, P.M., Coggins Jr., C.W., 1983. Maturity studies of avocado fruit based on picking dates and dry weight. J. Am. Soc. Hort. Sci. 108, 390-394.

Mizrach, A., Flitsanov, U., 1996. Predicting avocado shelf life by an ultrasonic nondestructive method. Acta Hortic., no. 421.

Mizrach, A., Galili, N., Rosenhouse, G., 1989. Determination of fruit and vegetable properties by ultrasonic excitation. Trans. ASAE 32, 2053-2058. 
Mizrach, A., Galili, N., Rosenhouse, G., Teitel, D.C., 1991. Acoustical, mechanical and quality parameters of winter grown melon tissue. Trans. ASAE 34, 2135-2138.

Mizrach, A., Galili, N., Rosenhouse, G., 1992. Half-cut fruit response to ultrasonic excitation. ASAE Paper No. 923017. Am. Soc. Agric. Eng., St. Joseph, MI, USA.

Mizrach, A., Galili, N., Rosenhouse, G., 1994. Method and a system for non-destructive determination of quality parameters in fresh produce. Israel Patent No. 109406. USA Patent No. 5589209 (December 31, 1996). French Patent Application No. 9504869 (April 24, 1995).

Mizrach, A., Galili, N., Gan-mor, S., Flitsanov, U., Prigozin, I., 1996. Model of ultrasonic parameters to assess avocado properties and shelf life. J. Agric. Eng. Res. 65, 261-267.

Zauberman, G., Fuchs, Y., 1981. Effect of wounding on 'Fuerte' avocado ripening. HortScience 16, 496-497. 